\title{
Retrieval of Salt Marsh Above-Ground Biomass from High-Spatial Resolution Hyperspectral Imagery Using PROSAIL
}

\author{
Rehman S. Eon ${ }^{1, *}$, Sarah Goldsmith ${ }^{2}$, Charles M. Bachmann ${ }^{1} \mathbb{1}$, Anna Christina Tyler ${ }^{2} \mathbb{(}$, \\ Christopher S. Lapszynski ${ }^{1}$, Gregory P. Badura ${ }^{1}$, David T. Osgood ${ }^{3}$ and Ryan Brett ${ }^{3}$ \\ 1 Chester F. Carlson Center for Imaging Science, Rochester Institute of Technology, Rochester, NY 14623-5603, \\ USA; bachmann@cis.rit.edu (C.M.B.); cs13172@rit.edu (C.S.L.); gpb6751@rit.edu (G.P.B.) \\ 2 Thomas H. Gosnell School of Life Sciences, Rochester Institute of Technology, Rochester, NY 14623-5603, \\ USA; sbg4917@rit.edu (S.G.); actsbi@rit.edu (A.C.T.) \\ 3 Department of Biology, Albright College, Reading, PA 19604, USA; dosgood@alb.edu (D.T.O.); \\ rmbrett97@gmail.com (R.B.) \\ * Correspondence: rse4949@rit.edu
}

Received: 25 April 2019; Accepted: 8 June 2019; Published: 11 June 2019

\begin{abstract}
Salt marsh vegetation density varies considerably on short spatial scales, complicating attempts to evaluate plant characteristics using airborne remote sensing approaches. In this study, we used a mast-mounted hyperspectral imaging system to obtain $\mathrm{cm}$-scale imagery of a salt marsh chronosequence on Hog Island, VA, where the morphology and biomass of the dominant plant species, Spartina alterniflora, varies widely. The high-resolution hyperspectral imagery allowed the detailed delineation of variations in above-ground biomass, which we retrieved from the imagery using the PROSAIL radiative transfer model. The retrieved biomass estimates correlated well with contemporaneously collected in situ biomass ground truth data $\left(R^{2}=0.73\right)$. In this study, we also rescaled our hyperspectral imagery and retrieved PROSAIL salt marsh biomass to determine the applicability of the method across spatial scales. Histograms of retrieved biomass changed considerably in characteristic marsh regions as the spatial scale of the imagery was progressively degraded. This rescaling revealed a loss of spatial detail and a shift in the mean retrieved biomass. This shift is indicative of the loss of accuracy that may occur when scaling up through a simple averaging approach that does not account for the detail found in the landscape at the natural scale of variation of the salt marsh system. This illustrated the importance of developing methodologies to appropriately scale results from very fine scale resolution up to the more coarse-scale resolutions commonly obtained in airborne and satellite remote sensing.
\end{abstract}

Keywords: hyperspectral imaging; high-resolution; salt marsh; biomass; Leaf Mass Index (LMA); Leaf Area Index (LAI); PROSAIL; radiative transfer model; Extended Fourier Amplitude Sensitivity Test (EFAST); Virginia Coast Reserve

\section{Introduction}

Coastal salt marshes form a critical transitional zone between land and sea and provide numerous ecological benefits including the removal and transformation of nutrients, essential habitat, protection from storm surges, support for coastal fisheries, and carbon sequestration [1-6]. The cumulative carbon stored in the biomass and deep sediments of vegetated coastal systems, including salt marshes-"Blue Carbon"-plays a critical role in global carbon sequestration $[7,8]$. However, primary production and carbon storage in marshes are highly variable over small spatial scales, leading to substantial uncertainty in total carbon sequestration [9]. Further, even in remote areas, these ecosystems 
are vulnerable to anthropogenic stressors, with rising sea-levels and shifting climates acting as a chief contributor to change in primary production and in some cases total marsh loss [8,10-15]. Coupled with other environmental stressors, such as coastal eutrophication, significant marsh loss is occurring [16-18]. Hence, it is crucial to have tools to assess both spatial and temporal variability in plant biomass and marsh health to predict future loss scenarios and guide conservation decisions.

Vegetation community structure and aboveground plant biomass (AGB) can be a good indicator of marsh health $[15,19,20]$. Although field data and in situ measurements are essential for monitoring change, it is not feasible to cover large spatial extents using these methods alone. Given this limitation, hyperspectral remote sensing can play an important role in mapping ecosystems over large spatial areas, and advances in remote sensing have significantly enhanced our ability to monitor wetland environments. Remote sensing data have been used, for example, to map species composition [21-24], classify vegetation [22-30], and monitor marsh dieback [31-34]. Mapping of change in vegetation communities over time has been useful to predict future prospects for marsh survival, even when conducted at the coarse scale of satellite imagery [35-38]. However, in marshes of the Western Atlantic, where the low marsh zone is dominated by Spartina alterniflora, biomass can change by an order of magnitude over short distances due to differences in invertebrate densities [39,40], elevation [41,42], or die off $[17,18]$. This is particularly true in the narrow fringing back-barrier marshes that line the Atlantic Coast of North America [42]. New methods are needed to capture the variability in salt marsh structure on the scale at which it occurs and provide accurate assessment of marsh condition. The critical scale on which change occurs requires centimeter-scale accuracy, and, in this study, we used a hyperspectral imaging system that provides imagery of a salt marsh system at resolutions varying from sub-centimeter- to centimeter-scale spatial resolution.

Statistical approaches and vegetation indices have been used to characterize carbon storage within different ecosystems (including wetlands) [43-45]. In some cases, estimates of plant biomass have been made [46], but with spatial resolution on the order of $1 \mathrm{~m}$ pixel size. In spatially heterogeneous marshes, even this scale may be too coarse to capture the detailed variability inherent in these systems and derive accurate models of biomass. Physics-based radiative transfer models, such as PROSAIL, have also been widely used to characterize biophysical properties of vegetation [47-58]. Physics-based models are capable of simulating the propagation of light and interaction with plant canopies, and interpreting vegetation reflectance in terms of plant structure and biophysical parameters [48]. The inversion of these physics-based models allows for targeted retrieval of different biophysical parameters. In this study, we inverted the radiative transfer model PROSAIL using optimization techniques to retrieve the aboveground leaf biomass from salt marsh vegetation, typically dominated by Spartina alterniflora.

For this study, we collected data using a high-efficiency hyperspectral imaging (HSI) sensor mounted on a telescopic mast [59]. The HSI system is capable of collecting imagery at very fine spatial resolutions $(\sim 0.5-3 \mathrm{~cm})$, which can provide the level of detail required for more accurate mapping of wetland ecosystems where the above-ground biomass varies substantially over small spatial scales due to variability in age, elevation, and proximity to die-off zones. In contrast to drone-based imaging systems, the oblique imaging geometry of our mast-mounted imaging system provides a unique view of the wetland canopy allowing in many instances access to views of both lower and upper canopy elements. No view of the canopy is without the potential for occlusion, thus, in the oblique view, parts of one plant may block another. Similarly, for an erectophile canopy, nadir views from a drone may be limited by the fact that upper canopy elements may obscure lower canopy elements and sediment may become a large part of the imagery with little of the plant surface directly exposed to the imaging system. Drone imagery is, of course, directly comparable to the nadir views from satellite systems, however, in some satellite imaging systems, off-nadir geometries are possible offering the possibility of oblique views of vegetation canopies. Our mast geometry for this study was limited to $\pm 34^{\circ}$ degrees from the horizon, however, in the future, we plan to modify the configuration to obtain a broader range of viewing geometries that can be compared more directly with satellite oblique views. 
The specific objectives of our study were to: (1) retrieve biophysical parameters from inversion of the PROSAIL model; (2) compare retrieved results with ground-based biophysical measurements; (3) evaluate how the model performs across gradients of marsh elevation, age, and heterogeneity; and (4) consider the effect of spatial scale on retrieved estimates of biomass.

\section{Field Survey}

\subsection{Study Area}

The work was conducted at the the Virginia Coast Reserve Long Term Ecological Research site on the Atlantic coast of the Delmarva Peninsula $[14,41,42,60]$. Hog Island $\left(37^{\circ} 25^{\prime} 5.91^{\prime \prime} \mathrm{N}, 75^{\circ} 41^{\prime} 36.71^{\prime \prime} \mathrm{W}\right)$, a $10 \mathrm{~km}$ long by $2.5 \mathrm{~km}$ wide barrier island roughly $14 \mathrm{~km}$ from the Peninsula, is typical of Western Atlantic barrier islands (Figure 1). The island, predominantly uninhabited since the mid-1900s and owned by The Nature Conservancy, is bounded on the eastern shore by the Atlantic Ocean and on the western shore by Hog Island Bay, a shallow coastal lagoon [61]. S. alterniflora is the dominant macrophyte in the marsh that fringes the lagoonal shore of the island, where it forms a classic zonation pattern of tall form plants in the low marsh, and short form in the mid and high zones [60]. In 1962, a strong nor'easter deposited nearly $1 \mathrm{~m}$ of sand on the southern end of the island, burying the existing marsh and elevating the intertidal platform [62]. Vegetation recolonized at different rates across the overwash fan, creating a chronosequence of different aged marshes. We define marsh age as the time at which S. alterniflora was first detected in aerial imagery. At the time of this study the younger marshes varied in age from 6 (established in 2011) to 43 years (established in 1974) old. The oldest marsh in our study was present on navigational maps dating back to at least 1850 , and was thus at least 170 years old in 2017 [42,63]. The chronosequence marshes are experiencing both erosion [12,14] and expansion, and are punctuated by patches of marsh die off (Tyler pers. obs). The resulting heterogeneity in marsh age and health makes this site ideal for the evaluation of biomass, as the aerial biomass of S. alterniflora varies by more than two orders of magnitude $[41,42,60,63]$. The research presented here primarily focused on the low to mid marsh zones, and on the retrieval of $S$. alterniflora biomass.
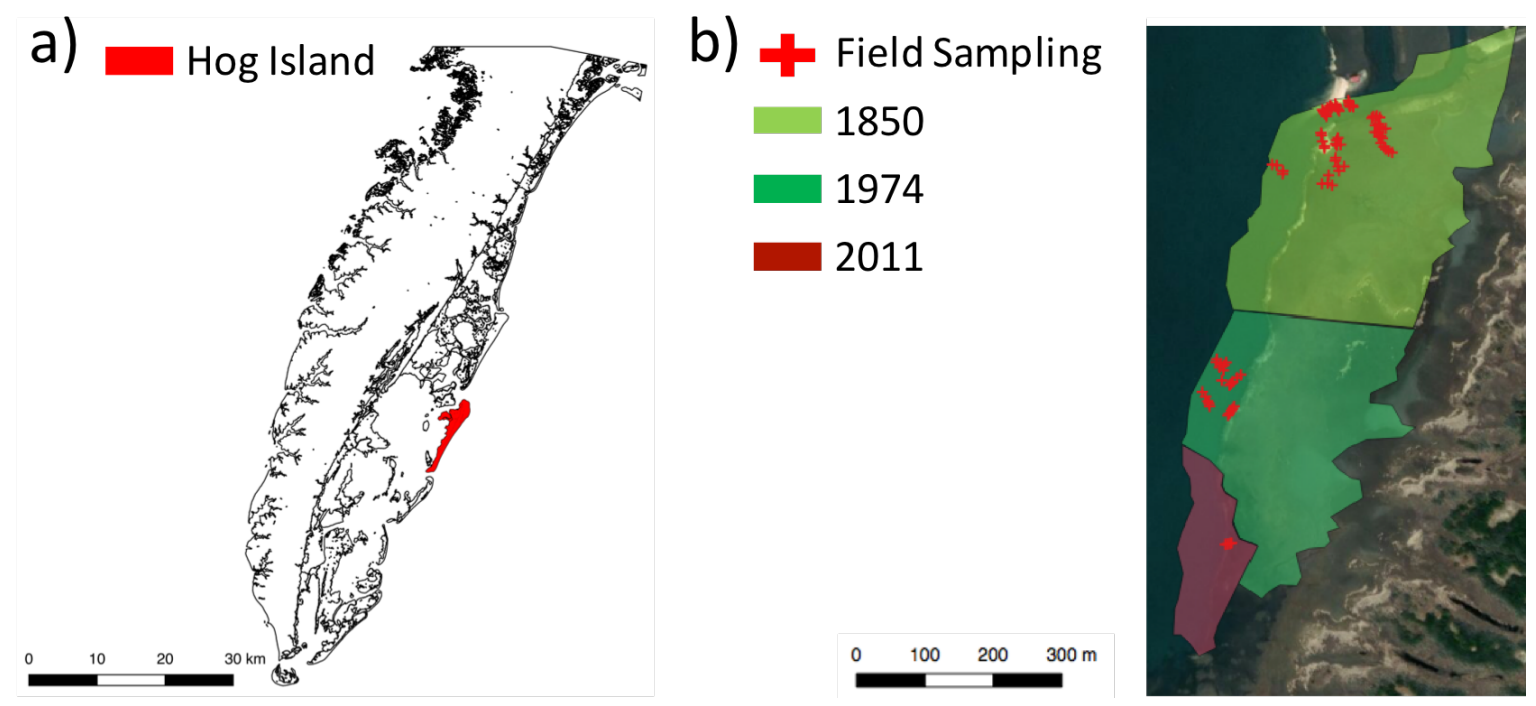

Figure 1. (a) Site Map of the Delmarva Peninsula, VA, including the barrier islands, estuaries, and shallow bays of the VCR/LTER, with Hog Island shown in red. (b) Our study site during the 2017 field campaign on Southern Hog Island. The figure shows the in situ measurements used in this study, covering marshes of three different ages established between $~ 1850$ to 2011 .

A major field campaign was conducted in the summer of 2017 to characterize and map the salt marsh ecosystem in southern Hog Island, as shown in Figure 1. The long-term objective of the study 
is to accurately model carbon storage within salt marsh environments across various spatial scales using very fine-scale hyperspectral imaging. Within the context of the larger team effort, the focus of the work presented herein was to estimate the aboveground biomass of S. alterniflora using PROSAIL across the different aged marshes in the southern part of Hog Island. The sampling sites during this first of several campaigns appear in Figure 1b. These spanned all three marsh ages shown, but within the available time and manpower of the first campaign, our sampling initially emphasized the marshes from 1850 and 1974. Sampling within individual marshes was designed to cover the spatial variations in biomass observed in the marsh system, and, where possible, we aimed to have 10-15 field ground truth points per hyperspectral scene. Future work will emphasize data taken from multiple years and probe the relationship between biomass and marsh age more completely.

\subsection{In Situ Measurements}

We collected ground truth biomass data in 48 plots spanning the different aged marshes in the field of view of our hyperspectral imaging system. In all ground-truth plots, the total number of culms and height to the tallest leaf of the first 10 culms along a diagonal transect through the plot were measured within a $0.25 \mathrm{~m}^{2}$ or $0.125 \mathrm{~m}^{2}$ quadrat. The plant height (mean \pm standard deviation (minimum-maximum)) for the 1850, 1974 and 2011 marshes was $42.7 \pm 18.6$ (5-96), $30.6 \pm 11.8$ (8-84), and $55.8 \pm 10.0$ (18-86), respectively. A height/weight regression was applied to these measurements to obtain total aboveground biomass per plot, as described in [42,64]. Briefly, in three $0.25 \mathrm{~m}^{2}$ randomly selected plots per marsh site, all S. alterniflora culms were clipped and cleaned of sediment. The height to the tallest leaf of 10-15 randomly selected culms was measured, and individual plants were dried at $60^{\circ} \mathrm{C}$ for $24 \mathrm{~h}$ to obtain individual dry weights that were then used to develop allometric regression equations for each marsh. The remaining culms were dried in bulk to verify the regression. The regressions relating culm heights to the dry weights for the three different marsh ages are defined by the following equations:

$$
\begin{aligned}
& 1850 \text { Marsh Site: } y=0.0007 x^{2}-0.005 x\left(R^{2}=0.92\right) ; \\
& 1974 \text { Marsh Site: } y=0.0009 x^{2}-0.0085 x\left(R^{2}=0.89\right) ; \\
& 2011 \text { Marsh Site: } y=0.0009 x^{2}-0.0042 x\left(R^{2}=0.92\right) ;
\end{aligned}
$$

where $y$ represents the individual culm biomass and $x$ is the culm height.

\section{Hyperspectral Imaging Sensor}

\subsection{Design and Instrumentation}

A major part of the 2017 field campaign focused on imaging the salt marsh vegetation using a state-of-the-art hyperspectral imaging system [59]. The hyperspectral imager, a Headwall VNIR Micro-hyperspec High Efficiency E-series [65], is a pushbroom system providing spectral measurements with 16-bit dynamic range from 400 to $1000 \mathrm{~nm}$ with 371 spectral bands and 1600 across-track spatial pixels. Figure 2 illustrates the different components and imagery collected by the system. 

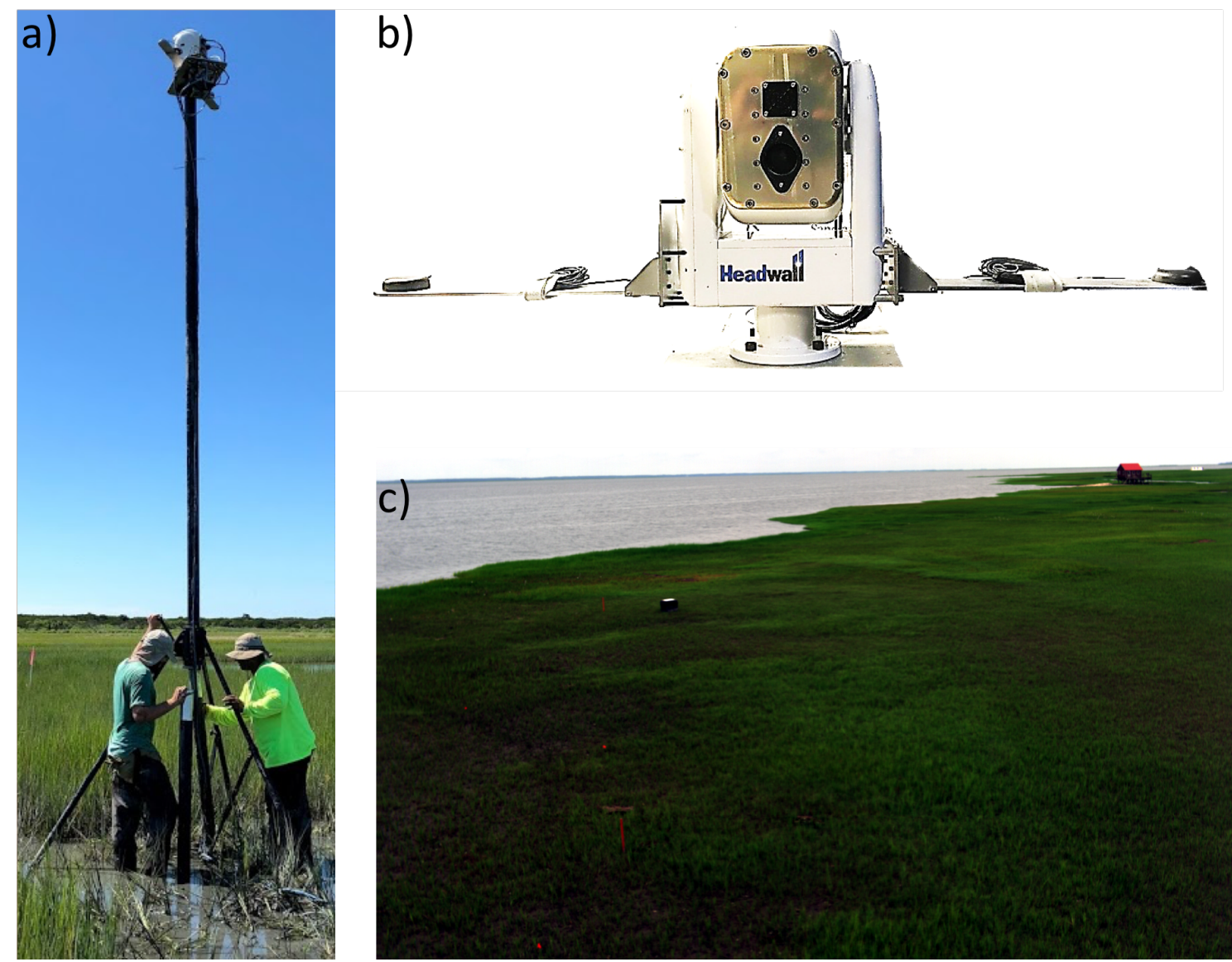

Figure 2. (a) Our HSI system being deployed in the field atop our BlueSky telescopic mast. (b) The different components of the HSI system. The Headwall hyperspectral sensor is housed within a maritime-rated General Dynamics Vector 20 pan-tilt unit. Our HSI system also incorporates a Vectornav VN-300 IMU-GPS to provide pointing information and GPS time-stamps. (c) A typical hyperspectral image obtained by our system on Hog Island at the VCR LTER.

The HSI sensor resides within a maritime-rated General Dynamics Vector 20 pan-tilt unit [66]. The pan-tilt unit can cover the angular range from $-34^{\circ}$ to $34^{\circ}$ in pitch, and $-175^{\circ}$ to $175^{\circ}$ in yaw. In practice, any azimuthal view orientation can be obtained simply by physically rotating the mast; however, full $360^{\circ}$ coverage of the landscape was possible without rotating the mast because the field of view of our imaging system was $57^{\circ}$ with the $12 \mathrm{~mm}$ lens that we typically used. The imaging system also hosts a Vectornav VN-300 IMU-GPS [67] to provide pointing information and GPS time-stamps. In the field, the HSI system is placed on top of a BlueSky AL-3 (15 m) telescopic mast [68], which is designed to be raised 1-15 $\mathrm{m}$ above the ground [59].

From the pan-tilt unit mounted on the telescopic mast, the hyperspectral imaging system can capture scenes from multiple viewing geometries, which allowed us to perform hyperspectral Bidirectional Reflectance Distribution Function (BRDF) measurements from the imaging sensor [59]. The ability to perform measurements at different heights, using the telescopic mast, also allowed us to observe the effect that spatial resolution has on hyperspectral imagery of a particular scene. The sensor can also be used as a low-rate video system, providing hyperpsectral measurements at frame-rates (rate of acquisition of a line of hyperspectral pixels) at up to $250 \mathrm{~Hz}$, leading to full hyperspectral scenes of size 1600 across-track $\times 212$ along track spatial pixels and 371 spectral bands at low video rates of $1.5 \mathrm{~Hz}$ [59]. The hyperspectral scenes described in this paper were acquired at slower scan rates and longer integration times and typically had larger along-track spatial pixel dimensions. 


\subsection{Image Acquisition and Processing}

We acquired hyperspectral imagery using the Headwall system described in Section 3.1 during the 2017 field survey contemporaneously with the in situ measurements. The portable configuration of our system enabled us to collect data over a large spatial extent in the southern part of Hog Island. The system captured imagery from areas with three different marsh ages: $\geq 170,56$, and 7 years. The HSI system, which is inside a pan-tilt unit and mounted upon a telescopic mast, acquired imagery from multiple viewing geometries and at various spatial resolutions. The hyperspectral imagery captured had a ground sampling distance (GSD) typically between 0.5 and $3 \mathrm{~cm}$, which provided a level of detail not usually available with most traditional remote sensing systems. The instrument design and collection method of the system produced varying GSD for each along-track pixel captured. As the line scanning unit was swept vertically across a scene, pixels capturing the foreground (bottom of image) had smaller GSD $(0.5 \mathrm{~cm})$ than those capturing information in the background (top of image), where GSD was $3 \mathrm{~cm}$. This high spatial resolution is crucial for studying wetland ecosystems, which have such high heterogeneity.

Our HSI system was characterized in our lab at RIT using our LabSphere Helios Integrating Sphere, which is coupled to an on-board calibrated spectrometer to acquire calibrated spectral radiance $\left(\mathrm{Wm}^{-2} \mathrm{sr}^{-1} \mathrm{~nm}^{-1}\right)$ from the raw digital number (DN) collected by the Headwall imaging system [59]. The placement of Spectralon ${ }^{\circledR}$ panels within the scene enabled the conversion of the imagery into surface reflectance. Using a Garmin RTK GPS TRM55971, we also conducted GPS surveys of fiducials placed in each scene, allowing us to geo-register the imagery. The number of ground control points (GCPs) used to geo-register the images varied between 4-12. The HSI images were registered using either first-, second- or third-order polynomial equations. The registration accuracy of the geo-referenced images was within approximately 1-10 cm, depending on the number of fiducials present within the scene.

\section{The PROSAIL Radiative Transfer Model}

\subsection{PROSAIL: Model Overview}

The radiative transfer model PROSAIL combines the canopy reflectance model SAIL with the leaf optical properties model PROSPECT [48,69-71]. The model simulates the hemispherical reflectance of plant canopies from the visible near-infrared (VNIR) to the short wave-infrared (SWIR), 400-2500 nm, with a spectral resolution of $1 \mathrm{~nm}$.

The PROSPECT model, based on the plate model, simulates canopy spectra as a function of leaf mesophyll structure $(\mathrm{N})$, chlorophyll $a+b$ concentration $\left(\mathrm{C}_{a b}\right)$, leaf water content $\left(\mathrm{C}_{w}\right)$, leaf mass area (LMA), brown pigments $\left(C_{b p}\right)$, and total carotenoid content $\left(C_{c x}\right)[69,72,73]$. SAIL simulates the bidirectional reflectance of the canopy using the following inputs: leaf reflectance obtained from PROSPECT, leaf inclination distribution function (LIDF), leaf area index (LAI), the sensor and solar geometries (zenith and azimuth angles), the hotspot effect (hspot), and the soil brightness factor ( $\rho$ soil) $[48,70,71]$. The factor, $\rho$ soil, is a scaling parameter that accounts for changes in the brightness of the soil due to the presence of moisture and soil roughness [74,75]. The LIDF is a key parameter describing the angular orientation of leaves in vegetation, and is an important variable for characterizing the plant structure. The LIDF generally describes six different types of plant structure: planophile, erectophile, plagiophile, extremophile, spherical, and uniform. In the model, the LIDF is defined by two different parameters, LIDFa and LIDFb, which describe the average leaf slope and the distribution bimodality, respectively [76].

\subsection{PROSAIL: Inversion Methodology}

In this study, we inverted the PROSAIL model to retrieve the above ground biomass from hyperspectral data collected during the 2017 field campaign. Our approach for the inversion of PROSAIL used a simplex-based search method, the Nelder-Mead Simplex Method [77]. 
This optimization technique minimizes the residual between the estimated reflectance from the PROSAIL model and the measured reflectance from our mast-based HSI system. The ranges (minimum and maximum) of the input parameters required for the inversion of the PROSAIL model are summarized in Table 1. The optimization technique attempts to find the best combination of input values for the PROSAIL model that minimizes the residual between the estimated and measured reflectance. Based on assessments from our field campaign, we found that the leaf area distribution of S. alterniflora has an erectophile structure. This was modeled in PROSAIL by setting LIDFa $=1$ and $\mathrm{LIDFb}=0$. We set the $\mathrm{C}_{b p}$ to zero in our inversion, since the data were collected during the growing season. The hspot was defined in terms of the LAI (hspot $=0.5 / \mathrm{LAI}$ ) [78,79]. The range of other variables in the PROSAIL model were selected based on previous studies and field measurements. We estimated the AGB as the product of the leaf mass area and leaf area index (LMA $\times$ LAI) [80].

Table 1. The input parameters of the PROSAIL model with units and range (minimum and maximum) used in the inversion detailed in this paper.

\begin{tabular}{ccccc}
\hline Model & Parameter & Symbol & Unit & Range or Fixed Value \\
\hline PROSPECT & Leaf Structure Parameter & $\mathrm{N}$ & $\mathrm{N} / \mathrm{A}$ & $1-1.25$ \\
& Chlorophyll a+b Content & $\mathrm{C}_{a b}$ & $\mu \mathrm{g} / \mathrm{cm}^{-2}$ & $10-101$ \\
& Equivalent Water Thickness & $\mathrm{EWT}$ & $\mathrm{cm}$ & $0.001-0.02$ \\
& Leaf Mass Area & $\mathrm{LMA}$ & $\mathrm{g} / \mathrm{m}^{-2}$ & $20-1000$ \\
& Brown Pigment & $\mathrm{C}_{b p}$ & $\mathrm{~N} / \mathrm{A}$ & 0 \\
& Carotenoid Content & $\mathrm{C}_{c x}$ & $\mu \mathrm{g} / \mathrm{cm}^{-2}$ & $1-20$ \\
\hline SAIL & Leaf Area Index & $\mathrm{LAI}$ & $\mathrm{m}^{2} \mathrm{~m}^{-2}$ & $1-10$ \\
& Hot Spot Factor & $\mathrm{hspot}$ & $\mathrm{N} / \mathrm{A}$ & $0.5 / \mathrm{LAI}$ \\
& Soil Factor & $\rho$ soil & $\mathrm{N} / \mathrm{A}$ & $0.2-1$ \\
& Two Leaf Inclination Distribution function (LIDF) & LIDFa/LIDFb & $\mathrm{N} / \mathrm{A}$ & $1 / 0$ \\
& Sun Zenith Angle & $\mathrm{sza}$ & $\mathrm{deg}$ & $/$ \\
& View Zenith Angle & $\mathrm{vza}$ & $\mathrm{deg}$ & $/$ \\
& Relative Azimuth Angle & raa & $\mathrm{deg}$ & $/$ \\
\hline
\end{tabular}

Over the years, many studies have demonstrated the use of only a limited number of spectral bands to efficiently describe the reflectance spectra of various materials, e.g., soil, water, vegetation, and snow [81-84]. Optimal spectral sampling has also been widely used in various studies involving PROSAIL [81,85-88]. In our work, we had a similar objective of finding optimal wavelengths to perform our inversion to retrieve above ground biomass. We investigated the sensitivity of the PROSAIL model to variations of the different input parameters reported in Table 1. The use of sensitivity analysis (SA) provides us the opportunity to observe the dependence of models on each individual input parameter. SA helps us to understand model behavior and its fidelity in describing real-world phenomenology [89]. We simulated PROSAIL a total of 70,000 times for the range (minimum-maximum) of its model parameters. The SA used in the study was the Extended Fourier Amplitude Sensitivity Test (EFAST), which has been applied to remote sensing data including in PROSAIL studies [89-92]. The EFAST computes the total contribution of each model parameter by considering the associated variance of the model output (in our case this is the variability in the reflectance) [89]. The total contribution includes both the effect of the individual input parameter as well as the interactions between all of the parameters.

The results from the EFAST are shown in Figure 3. We report the SA only for wavelengths in the VNIR (400-1000 nm), since this was the operational wavelength range of our hyperspectral imaging system. The two model parameters of interest in our analysis were the LMA and LAI. The impact of LAI was most noticeable in the wavelength range of 400-500 nm, accounting for 65-75\% of the variation. In this wavelength range, the impact of the other variables is significantly reduced (typically less than 25\%). Similarly, in the wavelength range of 720-1000 nm, the LMA was expressed most strongly compared to other model inputs, accounting for 50-75\% or more of the variability, while the contribution due to other inputs were again typically well below $25 \%$. This sensitivity 
analysis provided us with a range of wavelengths (400-500 nm and 720-1000 nm) to perform our inversion, which integrated 235 out of the 371 bands of the mast-based HSI system used in this study. By incorporating the optimal wavelength ranges into the inversion methodology, we avoided common pitfalls typically observed with optimization techniques, such as the risks of local "false" minima in the parameter space. The inversion scheme to retrieve aboveground biomass as well as our methodology to collect/process hyperspectral imagery is illustrated in Figure 4.
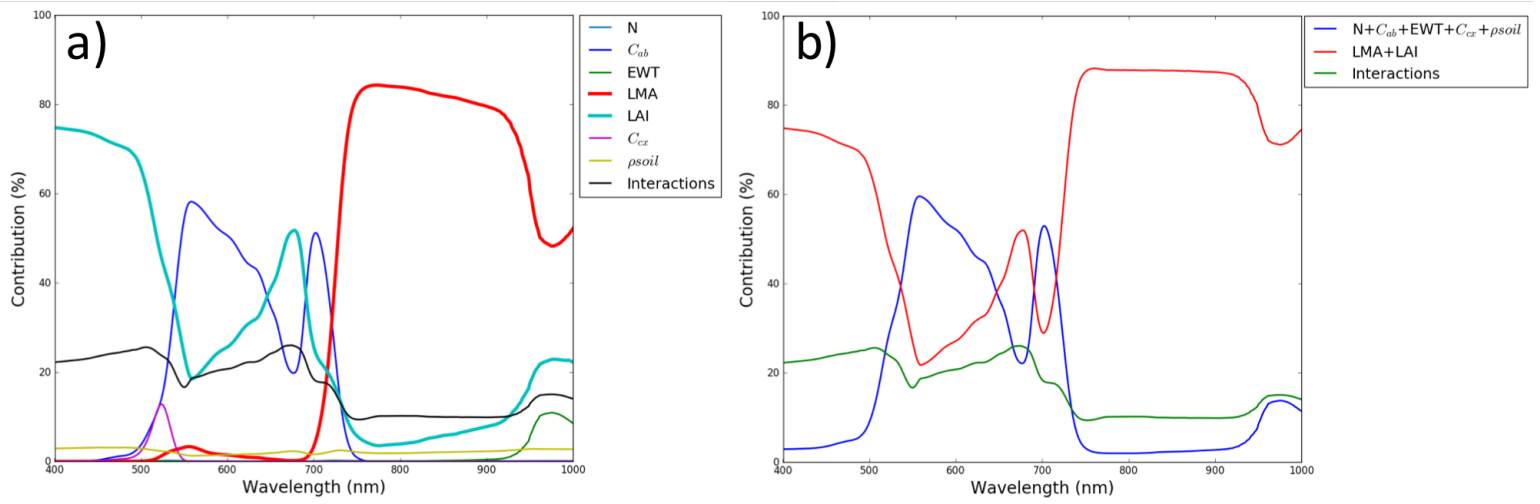

Figure 3. Results of the EFAST study illustrating how variation in PROSAIL inputs affects the output reflectance. The SA is only reported for wavelengths in the VNIR (400-1000 nm). In (a) we have plotted the contribution of each individual PROSAIL model input, while in (b) we have combined the model parameters of interest for our study (LMA and LAI) and all other inputs. The results from the SA provided us with the range of wavelengths (400-500 $\mathrm{nm}$ and $720-1000 \mathrm{~nm})$ to perform the inversion, where the contribution by LMA and LAI is significantly higher than all other model inputs.

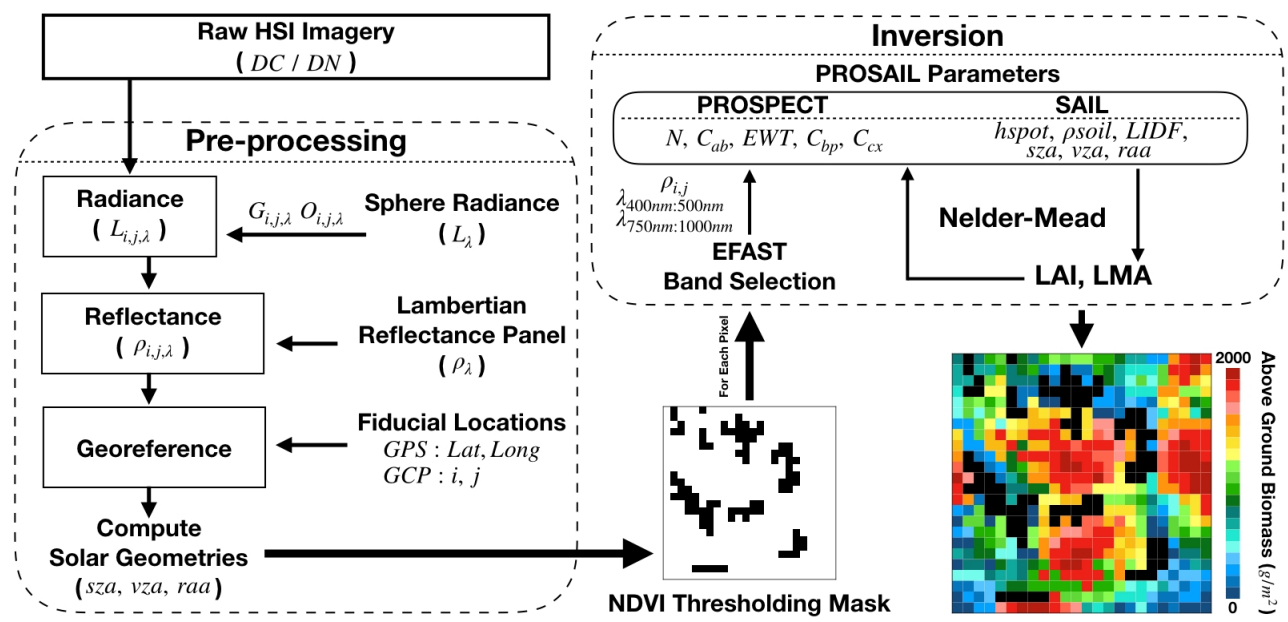

Figure 4. Overview of the inversion scheme to retrieve aboveground biomass of Spartina alterniflora from imagery collected by a ground-based HSI system. After data preprocessing, the NDVI threshold mask is used to remove soil pixels from the image in the analysis. EFAST provides band selection, while optimization of the PROSAIL model to obtain LAI and LMA uses the Nelder-Mead algorithm [77].

\subsection{PROSAIL: Spatial Resampling}

In this work, we also wanted to illustrate the effects of spatial resolution on the retrieved PROSAIL salt marsh biomass. To assess the effects of spatial scaling, we binned collected imagery to reduce image resolution by factors of 4 and 100. These scale factors allowed us to consider, respectively, the effects of both relatively moderate vs. large changes in spatial scale. To preserve global scaling 
across an image, each row was binned independently based upon a predefined window size. To reduce spatial resolution by a factor of 4 , for example, we constructed an averaging filter window 4 times the original GSD. Thus, a $2 \mathrm{~cm}$ wide window was constructed for a row containing pixels of $0.5 \mathrm{~cm}$ GSD. Neighboring pixels that fell within the window bounds were averaged to obtain a single reflectance.

\section{Results}

Biomass across the three sites varied substantially from roughly 30 to $1000 \mathrm{~g} / \mathrm{m}^{2}$, with the greatest range in the oldest marsh, and the lowest values in the 35-year-old marsh (Figure 5). Biomass results are generally consistent with those observed previously in these marshes [42,63] and are representative of the high variability that occurs in fringing barrier island marshes over relatively short spatial scales $(1-10 \mathrm{~m})$. Figure 5 demonstrates a relatively good relationship between in situ measured above-ground biomass and estimates from the inversion of PROSAIL (the measured and estimated AGB of Spartina alterniflora: $\mathrm{R}^{2}=0.73$; normalized root mean square error $(\mathrm{NRMSE})=$ $23.40 \%$ ). In Figure 6, we show examples of the retrieved biomass estimate of the PROSAIL model biomass for individual hyperspectral pixels in the scene. However, to compare against our ground truth quadrats of size $0.25 \mathrm{~m}^{2}$, we averaged the reflectance in our hyperspectral imagery over the region of the quadrat and compared the retrieved biomass from PROSAIL against that determined directly from the quadrat through laboratory analysis. This comparison provided the results shown in Figure 5. Where the data in our present analysis (Figure 5) show greater scatter, noise is likely due to registration errors of the ground truth quadrat within the hyperspectral scene, mixed pixels (vegetation/soil) or soil pixels not fully removed by the NDVI spectral test (Figure 4), obscuration, and shadows. The scatterplot in Figure 5 does not show particular bias for one age fitting better than another to the regression line, but a more comprehensive analysis as a function of age will require samples from subsequent campaigns to fill in data gaps, for example, for the 2011 marsh.

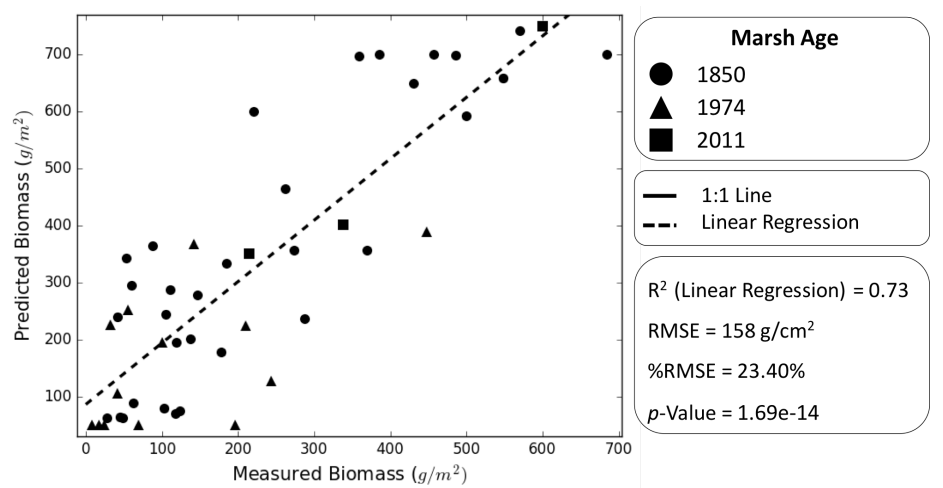

Figure 5. Comparison between measured above ground biomass $\left(\mathrm{g} / \mathrm{m}^{2}\right)$ and values estimated through the inversion of PROSAIL.

At the pixel level, as noted above, we applied the inversion methodology to hyperspectral images collected during our 2017 field survey. The inversion was applied to images from three different marsh ages: the marshes originating in 2011, 1974, and 1850. AGB maps from six selected images collected from our HSI system are shown in Figure 6. These six HSI images were collected simultaneously with the in situ measurements, which were used for the validation of the PROSAIL inversion methodology shown in Figure 5. The HSI images had a GSD ranging from 0.5 to $3 \mathrm{~cm}$. The very high resolution scale hyperspectral imagery obtained in this study, at the sub-centimeter-to-centimeter scale, addresses a critical need in that the imagery is precisely at the scale where the variation in vegetation structure and plant biomass can best be characterized, that is, by looking directly at components of the individual plants and how these components vary across the landscape. The retrieved AGB from these images shows good correlation with past and present field surveys. For example, the AGB maps indicate 
higher marsh densities on the berm, while die-off areas show lower biomass. The 2011 marsh site generally had taller and denser Spartina alterniflora compared to the other two aged marsh sites, as indicated by the higher AGB observed in our inversion results in Figure 6.

а)

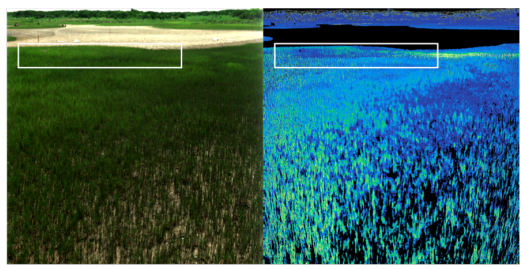

c)

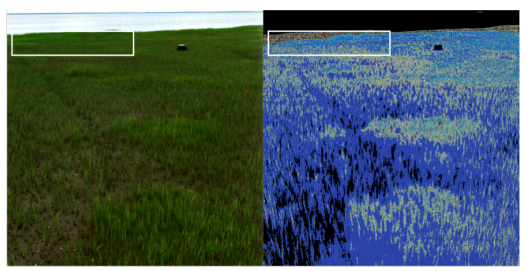

b)

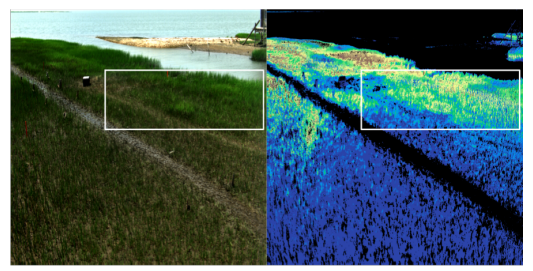

d)

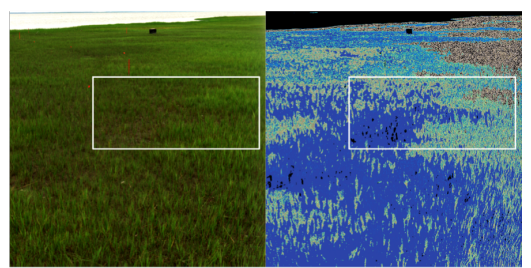

e)
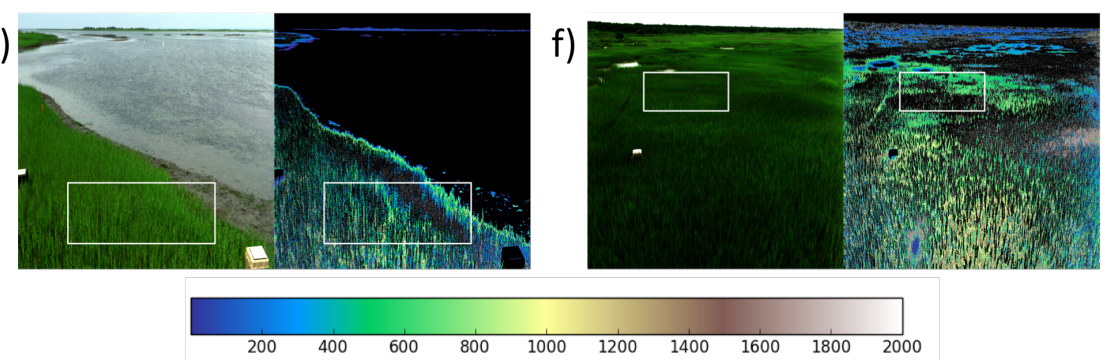

Above Ground Biomass $\left(\mathrm{g} / \mathrm{m}^{2}\right)$

Figure 6. Hyperspectral scenes (left image in each pair) and corresponding retrieved above ground biomass $\left(\mathrm{g} / \mathrm{m}^{2}\right)$ (right image in each pair) for marshes of various age: (a,b) 1850; (c,d) 1974; and $(\mathbf{e}, \mathbf{f}) 2011$.

To evaluate how the biomass estimates shift as the spatial resolution changes, and make comparisons with the resolution that may be more characteristic of that obtained from aerial imagery, we downsampled the imagery to evaluate how resolution impacts the accuracy of assessment. We selected certain region of interests (ROIs) from the AGB maps in Figure 6 (the ROIs are shown in white) to observe the influence of spatial heterogeneity and resolution on the overall assessment of the biomass. These results are shown in the form of histograms in Figure 7. The first column in Figure 7 shows the histogram at the original spatial resolution, in the second column the spatial resolution was changed by a factor of four, and in column three by a factor of a hundred. The statistics for the ROIs are detailed in Table 2. This table and the histograms show that the standard deviation represents a large fraction of the mean biomass retrieved in the original image resolution. As the imagery spatial resolution is progressively degraded, the mean retrieved biomass can shift significantly, for example, in the 2011 marsh site for the ROI labeled "medium zone with die-off". As spatial resolution of the input imagery decreased, the trend was that these shifts in the mean appeared to depend on the relative density of the marsh site. The mean of the lower biomass sites did not change substantially, however, larger changes in the mean biomass occurred for the higher biomass regions. 
a)
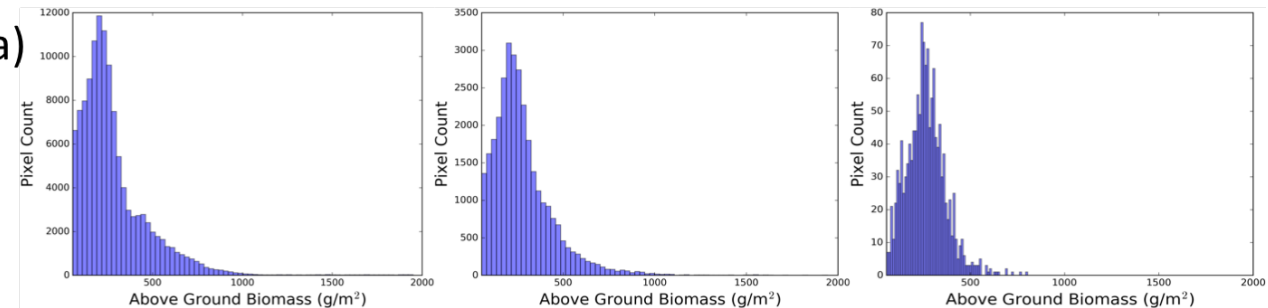

b)
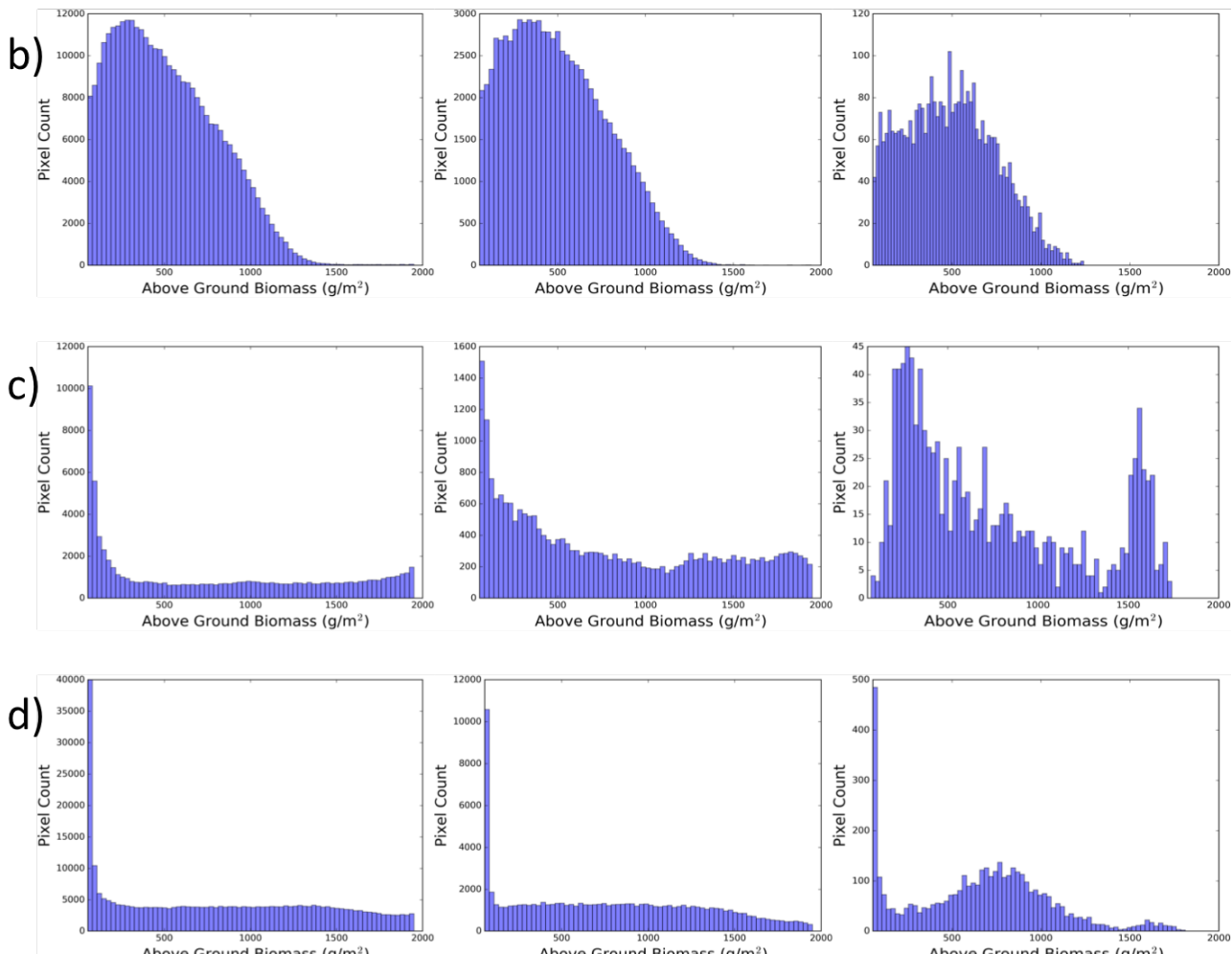

Above Ground Biomass $\left(\mathrm{g} / \mathrm{m}^{2}\right)$

Above Ground Biomass ( $\left.\mathrm{g} / \mathrm{m}^{2}\right)$

Above Ground Biomass $\left(\mathrm{g} / \mathrm{m}^{2}\right)$
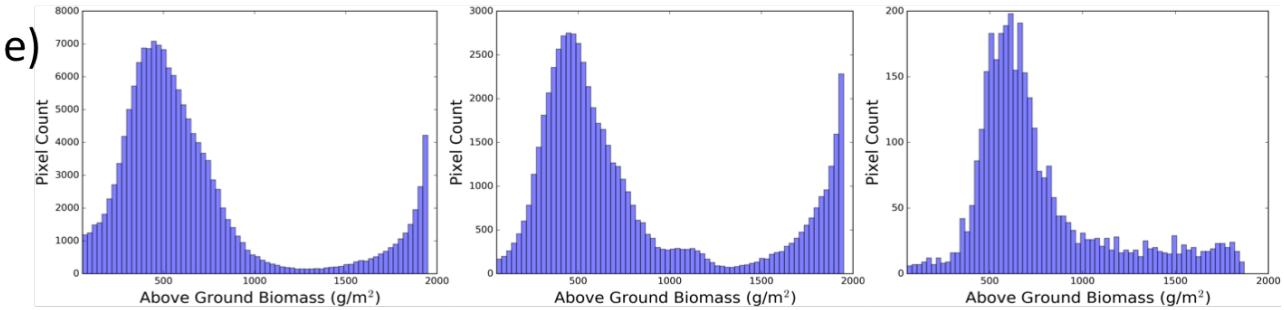

f)
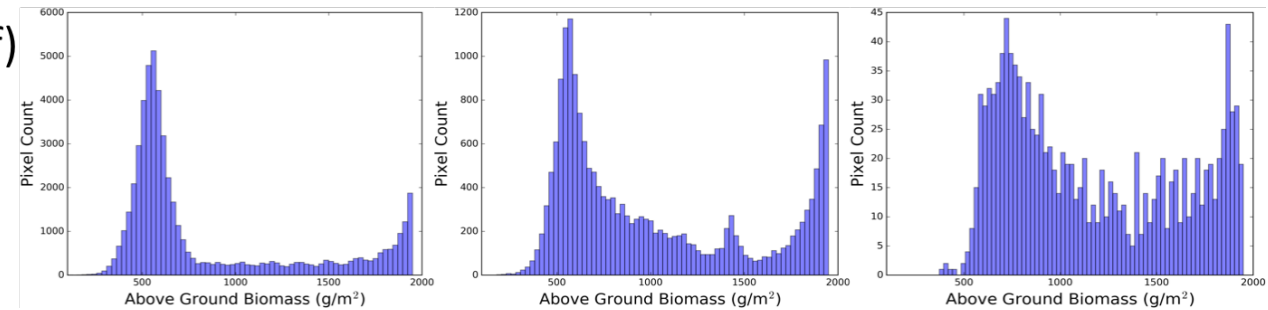

Figure 7. The spatial distribution of the retrieved AGB for ROIs (shown in white) from Figure 6 of the various marsh sites: (a) 1850 "short zone at panne edge"; (b) 1850 "tall zone at creek bank"; (c) 1974 "medium zone at lagoon edge"; (d) 1974 "short zone with hummock"; (e) 2011 "tall zone at lagoon edge"; and (f) 2011 "medium zone with die-off". The first column shows the histogram at the original spatial resolution, in the second column the spatial resolution has been changed by a factor of four, and in column three by a factor of one hundred. 
Table 2. The mean, standard deviation, skewness and kurtosis for the ROIs shown in Figures 6 and 7. The spatial resolution " 1 " is the original resolution, " 2 " the resolution was changed by a factor of four, and " 3 " by a factor of hundred.

\begin{tabular}{|c|c|c|c|c|}
\hline Spatial Resolution & Mean & Standard Deviation & Skewness & Kurtosis \\
\hline \multicolumn{5}{|c|}{ Marsh Site: 1850 "Short Zone at Panne Edge" } \\
\hline 1 & 288 & 203 & 2.56 & 11.43 \\
\hline 2 & 284 & 174 & 2.29 & 9.98 \\
\hline 3 & 270 & 108 & 0.94 & 2.23 \\
\hline \multicolumn{5}{|c|}{ Marsh Site: 1850 “Tall Zone at Creekbank” } \\
\hline 1 & 481 & 295 & 0.66 & -0.087 \\
\hline 2 & 473 & 901 & 0.58 & -0.38 \\
\hline 3 & 452 & 257 & 0.37 & -0.70 \\
\hline \multicolumn{5}{|c|}{ Marsh Site: 1974 “Medium Zone at Lagoon Edge" } \\
\hline 1 & 841 & 641 & 0.22 & -1.41 \\
\hline 2 & 793 & 566 & 0.40 & -1.12 \\
\hline 3 & 732 & 444 & 0.62 & -0.72 \\
\hline \multicolumn{5}{|c|}{ Marsh Site: 1974 "Short Zone With Hummock" } \\
\hline 1 & 822 & 584 & 0.21 & -1.23 \\
\hline 2 & 786 & 535 & 0.26 & -1.05 \\
\hline 3 & 656 & 396 & 0.25 & -0.27 \\
\hline \multicolumn{5}{|c|}{ Marsh Site: 2011 “Tall Zone at Lagoon Edge” } \\
\hline 1 & 683 & 480 & 1.53 & 1.35 \\
\hline 2 & 801 & 552 & 1.05 & -0.35 \\
\hline 3 & 773 & 365 & 1.25 & 1.06 \\
\hline \multicolumn{5}{|c|}{ Marsh Site: 2011 "Medium Zone with Die-off" } \\
\hline 1 & 858 & 501 & 1.13 & -0.28 \\
\hline 2 & 1008 & 507 & 0.69 & -0.99 \\
\hline 3 & 1149 & 437 & 0.41 & -1.22 \\
\hline
\end{tabular}

\section{Discussion and Conclusions}

We demonstrated a new approach to quantifying biomass in salt marsh systems using a novel mast-mounted hyperspectral imaging system [59]. This system provides pixels at sub-centimeter-scale spatial resolution, allowing the characterization of the marsh system at significantly higher spatial resolutions than typical airborne hyperspectral imaging systems. Imaging at this very fine spatial scale provides the opportunity to remotely retrieve and analyze small-scale details of coastal marsh ecosystems, which exhibit high spatial heterogeneity.

Using this fine-scale hyperspectral imagery at a range of salt marsh sites, which vary in biomass across an order of magnitude, as the input to a workflow that incorporates the PROSAIL radiative transfer model, we were able to successfully retrieve above-ground biomass at a resolution substantially greater than previously published work [22-30]. Our model output captured the high spatial heterogeneity of the system and retrieved AGB that correlated moderately well with ground-truth measurements $\left(R^{2}=0.73\right)$. During PROSAIL model inversion, the relative accuracy of the biomass retrieval result relied heavily on using optimal wavelengths derived from EFAST. By incorporating the optimal wavelength ranges into the inversion methodology, we avoided common pitfalls typically observed with optimization techniques, such as the risks of local "false" minima in the parameter space. We saw significant improvement in our retrieval of AGB by performing the inversion within the wavelength ranges of 400-500 nm and 720-1000 nm, compared with using the complete wavelength range of our HSI system. The $R^{2}$ value improved by a factor greater than 2 , increasing from 0.35 to 0.73 due to the incorporation of optimal wavelengths found by EFAST into the inversion methodology. 
Inspection of retrieved biomass products showed that variations followed observed patterns in the field setting, with, for example, high biomass values obtained in the tall S. alterniflora near creekbank edges and lower biomass values found in die-off patches and in the short zone near the salt panne (Figure 6).

Although our HSI system was capable of collecting imagery at very high spatial resolution, we still have mixed pixels of vegetation, sediment and water in our data, which impacted the overall accuracy of our model in retrieving AGB. The accuracy of the retrieved biomass was also affected by the geo-registration method utilized for the mast-mounted HSI system. We conducted GPS surveys of fiducials within our scene to geo-register the images. The registration accuracy of the geo-referenced images were within approximately $1-10 \mathrm{~cm}$, depending on the number of fiducials present within the scene. This affected our ability to precisely select ROIs where we collected ground-truth biomass data.

In this work, we also rescaled the retrieved PROSAIL salt marsh biomass to two different spatial scales $(\times 4$ and $\times 100)$ for selected regions within the marsh system in order to determine the applicability of the method across spatial scales. This rescaling revealed a loss of spatial detail (Figure 7) and a shift in the mean biomass in the region of interest (Table 2). For low biomass regions $\left(<500 \mathrm{~g} / \mathrm{m}^{2}\right)$, the retrievals were similar across the three scales. However, for higher biomass, the variation across scales increased, with underestimates at coarser scales in the mid-range of biomass, and a $34 \%$ overestimate at the coarsest scale for the highest biomass region. This shift is indicative of the loss of accuracy that may occur when scaling up through a simple averaging approach that does not account for the detail found in the landscape at the natural scale of variation of the salt marsh system. This suggests that coarse-scale imagery, such as that obtained from aerial systems, may not provide the accuracy needed to assess biomass and thereby proportional carbon sequestration potential in systems with high spatial heterogeneity, such as salt marshes, and that additional work to verify our ability to use such imagery is required. Similar discrepancies in scaling across platforms have been found in a variety of other remote sensing applications (e.g., [93-95]). Additional work to compare imagery collected simultaneously at different scales may help to reconcile accuracy issues associated with the retrieval of biomass across platforms. Our scaling analysis illustrates that simple averaging may introduce some error in the process of retrieving biomass likely because a simple average does not account for the structure found at the very fine scales of our imagery. Indeed, to be successful in scaling, modeling will have to account more completely for the spatial relationships present in the plant structures and how they vary across the landscape. Our very fine scale imagery gives us access to this information, and long-term will be useful in improving models.

Biomass products such as those that we have obtained can support other types of analyses-for example, the development of models related to plant stress in the salt marsh landscape. Plant stress can directly influence biomass and may be an important factor in determining ecosystem services such as carbon storage. While there have been prior studies examining the effects of various stressors on $S$. alterniflora biomass $[31,37,96]$, these models may be limited by the broad spatial scales of data acquisition when applied at the landscape level. Using our imaging system, we now have access to imagery at very high spatial resolutions ( sub-centimeter- to centimeter-scale). Spectral data have long been used to analyze the effects of stress on vegetation [96,97]; however, this enhanced spatial scale would allow us to observe the details of stress across the plant structure as opposed to over averages of multiple plants, which would normally be the scale observed in past remote sensing studies. The level of high spatial detail applied in this study may allow for better detection of spatially heterogeneous parameters such as salinity stress, oxidation-reduction potential, or leaf nitrogen content, which may be influencing biomass production. The level of high spatial detail applied in this study makes possible correlations with other plant biophysical measures as well as biophysical measures of the sediment surface, such as soil organic carbon, which are likely to be correlated with the above-ground biomass in salt marsh ecosystems [42]. In the long term, understanding these patterns of salt marsh stress and $\mathrm{C}$ sequestration are important for predicting marsh resilience. 
Author Contributions: Conceptualization, R.S.E., C.M.B., and A.C.T.; Methodology, R.S.E., C.M.B., and A.C.T.; Software, R.S.E.; Validation, R.S.E., C.M.B., S.G., A.C.T., C.S.L., and D.T.O.; Formal Analysis, R.S.E., C.M.B., and A.C.T.; Investigation, R.S.E., C.M.B., S.G., A.C.T., C.S.L., G.P.B., D.T.O., and R.B.; Resources, C.M.B. and A.C.T.; Data Curation, R.S.E., S.G., and C.S.L.; Writing-Original Draft Preparation, R.S.E., C.M.B., A.C.T., and S.G.; Writing-Review and Editing, R.S.E., C.M.B., A.C.T., S.G., and D.T.O.; Visualization, R.S.E., C.M.B., A.C.T., and C.S.L.; Supervision, C.M.B., A.C.T., and D.T.O.; Project Administration, C.M.B. and A.C.T.; and Funding Acquisition, C.M.B. and A.C.T.

Funding: The authors gratefully acknowledge funding from the RIT College of Science through a Dean's Research Initiation Grant (D-RIG), which supported this research. C. M. Bachmann and A. C. Tyler gratefully acknowledge support of their work by the National Geographic Explorers program under Grant NGS-382R-18. The authors are also grateful for support provided by NSF DEB Grants \#1237733 \#1832221 (VCR-LTER), which contributed to the fieldwork described in this paper.

Conflicts of Interest: The authors declare no conflict of interest.

\section{References}

1. Boesch, D.F.; Turner, R.E. Dependence of fishery species on salt marshes: The role of food and refuge. Estuaries 1984, 7, 460-468. [CrossRef]

2. Barbier, E.B.; Koch, E.W.; Silliman, B.R.; Hacker, S.D.; Wolanski, E.; Primavera, J.; Granek, E.F.; Polasky, S.; Aswani, S.; Cramer, L.A.; et al. Coastal ecosystem-based management with nonlinear ecological functions and values. Science 2008, 319, 321-323. [CrossRef]

3. Koch, E.W.; Barbier, E.B.; Silliman, B.R.; Reed, D.J.; Perillo, G.M.; Hacker, S.D.; Granek, E.F.; Primavera, J.H.; Muthiga, N.; Polasky, S.; et al. Non-linearity in ecosystem services: Temporal and spatial variability in coastal protection. Front. Ecol. Environ. 2009, 7, 29-37. [CrossRef]

4. Morgan, P.A.; Burdick, D.M.; Short, F.T. The functions and values of fringing salt marshes in northern New England, USA. Estuar. Coasts 2009, 32, 483-495. [CrossRef]

5. Chmura, G.L.; Anisfeld, S.C.; Cahoon, D.R.; Lynch, J.C. Global carbon sequestration in tidal, saline wetland soils. Glob. Biogeochem. Cycles 2003, 17. [CrossRef]

6. Kulawardhana, R.W.; Feagin, R.A.; Popescu, S.C.; Boutton, T.W.; Yeager, K.M.; Bianchi, T.S. The role of elevation, relative sea-level history and vegetation transition in determining carbon distribution in Spartina alterniflora dominated salt marshes. Estuar. Coast. Shelf Sci. 2015, 154, 48-57. [CrossRef]

7. Mcleod, E.; Chmura, G.L.; Bouillon, S.; Salm, R.; Björk, M.; Duarte, C.M.; Lovelock, C.E.; Schlesinger, W.H.; Silliman, B.R. A blueprint for blue carbon: Toward an improved understanding of the role of vegetated coastal habitats in sequestering CO2. Front. Ecol. Environ. 2011, 9, 552-560. [CrossRef]

8. Pendleton, L.; Donato, D.C.; Murray, B.C.; Crooks, S.; Jenkins, W.A.; Sifleet, S.; Craft, C.; Fourqurean, J.W.; Kauffman, J.B.; Marbà, N.; et al. Estimating global "blue carbon" emissions from conversion and degradation of vegetated coastal ecosystems. PLoS ONE 2012, 7, e43542. [CrossRef]

9. Chmura, G.L. What do we need to assess the sustainability of the tidal salt marsh carbon sink? Ocean Coast. Manag. 2013, 83, 25-31. [CrossRef]

10. Morris, J.T.; Sundareshwar, P.; Nietch, C.T.; Kjerfve, B.; Cahoon, D.R. Responses of coastal wetlands to rising sea level. Ecology 2002, 83, 2869-2877. [CrossRef]

11. Kathilankal, J.C.; Mozdzer, T.J.; Fuentes, J.D.; D'Odorico, P.; McGlathery, K.J.; Zieman, J.C. Tidal influences on carbon assimilation by a salt marsh. Environ. Res. Lett. 2008, 3, 044010. [CrossRef]

12. Fagherazzi, S.; Kirwan, M.L.; Mudd, S.M.; Guntenspergen, G.R.; Temmerman, S.; D'Alpaos, A.; Koppel, J.; Rybczyk, J.M.; Reyes, E.; Craft, C.; et al. Numerical models of salt marsh evolution: Ecological, geomorphic, and climatic factors. Rev. Geophys. 2012, 50, RG1002. [CrossRef]

13. Kirwan, M.L.; Mudd, S.M. Response of salt-marsh carbon accumulation to climate change. Nature 2012, 489, 550-553. [CrossRef]

14. McLoughlin, S.M.; Wiberg, P.L.; Safak, I.; McGlathery, K.J. Rates and forcing of marsh edge erosion in a shallow coastal bay. Estuar. Coasts 2015, 38, 620-638. [CrossRef]

15. Byrd, K.B.; O'Connell, J.L.; Di Tommaso, S.; Kelly, M. Evaluation of sensor types and environmental controls on mapping biomass of coastal marsh emergent vegetation. Remote Sens. Environ. 2014, 149, 166-180. [CrossRef]

16. Deegan, L.A.; Johnson, D.S.; Warren, R.S.; Peterson, B.J.; Fleeger, J.W.; Fagherazzi, S.; Wollheim, W.M. Coastal eutrophication as a driver of salt marsh loss. Nature 2012, 490, 388-392. [CrossRef] 
17. Alber, M.; Swenson, E.M.; Adamowicz, S.C.; Mendelssohn, I.A. Salt marsh dieback: An overview of recent events in the US. Estuar. Coast. Shelf Sci. 2008, 80,1-11. [CrossRef]

18. Osgood, D.T.; Silliman, B.R. From Climate Change to Snails. In Human Impacts on Salt Marshes: A Global Perspective; University of California Press: Orlando, FL, USA, 2009; pp. 231-252.

19. Morris, J.T.; Bowden, W.B. A Mechanistic, Numerical Model of Sedimentation, Mineralization, and Decomposition for Marsh Sediments 1. Soil Sci. Soc. Am. J. 1986, 50, 96-105. [CrossRef]

20. Swanson, K.M.; Drexler, J.Z.; Schoellhamer, D.H.; Thorne, K.M.; Casazza, M.L.; Overton, C.T.; Callaway, J.C.; Takekawa, J.Y. Wetland accretion rate model of ecosystem resilience (WARMER) and its application to habitat sustainability for endangered species in the San Francisco Estuary. Estuar. Coasts 2014, 37, 476-492. [CrossRef]

21. Klemas, V. Remote sensing of wetlands: Case studies comparing practical techniques. J. Coast. Res. 2011, $27,418-427$.

22. Wright, C.; Gallant, A. Improved wetland remote sensing in Yellowstone National Park using classification trees to combine TM imagery and ancillary environmental data. Remote Sens. Environ. 2007, 107, 582-605. [CrossRef]

23. Bachmann, C.M.; Donato, T.F.; Lamela, G.M.; Rhea, W.J.; Bettenhausen, M.H.; Fusina, R.A.; Du Bois, K.R.; Porter, J.H.; Truitt, B.R. Automatic classification of land cover on Smith Island, VA, using HyMAP imagery. IEEE Trans. Geosci. Remote Sens. 2002, 40, 2313-2330. [CrossRef]

24. Bachmann, C.M.; Bettenhausen, M.H.; Fusina, R.A.; Donato, T.F.; Russ, A.L.; Burke, J.W.; Lamela, G.M.; Rhea, W.J.; Truitt, B.R.; Porter, J.H. A credit assignment approach to fusing classifiers of multiseason hyperspectral imagery. IEEE Trans. Geosci. Remote Sens. 2003, 41, 2488-2499. [CrossRef]

25. Andrew, M.E.; Ustin, S.L. The role of environmental context in mapping invasive plants with hyperspectral image data. Remote Sens. Environ. 2008, 112, 4301-4317. [CrossRef]

26. Wang, C.; Menenti, M.; Stoll, M.P.; Belluco, E.; Marani, M. Mapping mixed vegetation communities in salt marshes using airborne spectral data. Remote Sens. Environ. 2007, 107, 559-570. [CrossRef]

27. Artigas, F.J.; Yang, J. Spectral discrimination of marsh vegetation types in the New Jersey Meadowlands, USA. Wetlands 2006, 26, 271-277. [CrossRef]

28. Hirano, A.; Madden, M.; Welch, R. Hyperspectral image data for mapping wetland vegetation. Wetlands 2003, 23, 436-448. [CrossRef]

29. Bachmann, C.M. Improving the performance of classifiers in high-dimensional remote sensing applications: An adaptive resampling strategy for error-prone exemplars (ARESEPE). IEEE Trans. Geosci. Remote Sens. 2003, 41, 2101-2112. [CrossRef]

30. Hladik, C.; Schalles, J.; Alber, M. Salt marsh elevation and habitat mapping using hyperspectral and LIDAR data. Remote Sens. Environ. 2013, 139, 318-330. [CrossRef]

31. Ramsey, I.; Rangoonwala, A. Canopy reflectance related to marsh dieback onset and progression in coastal Louisiana. Photogramm. Eng. Remote Sens. 2006, 72, 641-652. [CrossRef]

32. Ghosh, S.; Mishra, D.R.; Gitelson, A.A. Long-term monitoring of biophysical characteristics of tidal wetlands in the northern Gulf of Mexico-A methodological approach using MODIS. Remote Sens. Environ. 2016, 173, 39-58. [CrossRef]

33. Marsh, A.; Blum, L.K.; Christian, R.R.; Ramsey, E.; Rangoonwala, A. Response and resilience of Spartina alterniflora to sudden dieback. J. Coast. Conserv. 2016, 20, 335-350. [CrossRef]

34. McKee, K.L.; Mendelssohn, I.A.; D. Materne, M. Acute salt marsh dieback in the Mississippi River deltaic plain: A drought-induced phenomenon? Glob. Ecol. Biogeogr. 2004, 13, 65-73. [CrossRef]

35. Sun, C.; Fagherazzi, S.; Liu, Y. Classification mapping of salt marsh vegetation by flexible monthly NDVI time-series using Landsat imagery. Estuar. Coast. Shelf Sci. 2018, 213, 61-80. [CrossRef]

36. Campbell, A.; Wang, Y. Examining the influence of tidal stage on salt marsh mapping using high-spatialresolution satellite remote sensing and topobathymetric lidar. IEEE Trans. Geosci. Remote Sens. 2018, 56, 5169-5176. [CrossRef]

37. Ramsey, E., III; Rangoonwala, A.; Chi, Z.; Jones, C.E.; Bannister, T. Marsh dieback, loss, and recovery mapped with satellite optical, airborne polarimetric radar, and field data. Remote Sens. Environ. 2014, 152, 364-374. [CrossRef]

38. Campbell, A.; Wang, Y.; Christiano, M.; Stevens, S. Salt marsh monitoring in Jamaica Bay, New York from 2003 to 2013: A decade of change from restoration to Hurricane Sandy. Remote Sens. 2017, 9, 131. [CrossRef] 
39. Silliman, B.R.; Van De Koppel, J.; Bertness, M.D.; Stanton, L.E.; Mendelssohn, I.A. Drought, snails, and large-scale die-off of southern US salt marshes. Science 2005, 310, 1803-1806. [CrossRef]

40. Angelini, C.; Griffin, J.N.; van de Koppel, J.; Lamers, L.P.; Smolders, A.J.; Derksen-Hooijberg, M.; van der Heide, T.; Silliman, B.R. A keystone mutualism underpins resilience of a coastal ecosystem to drought. Nat. Commun. 2016, 7, 12473. [CrossRef]

41. Tyler, A.C.; Mastronicola, T.A.; McGlathery, K.J. Nitrogen fixation and nitrogen limitation of primary production along a natural marsh chronosequence. Oecologia 2003, 136, 431-438. [CrossRef]

42. Tyler, A.C.; Zieman, J.C. Patterns of development in the creekbank region of a barrier island Spartina alterniflora marsh. Mar. Ecol. Prog. Ser. 1999, 161-177. [CrossRef]

43. Burkart, A.; Aasen, H.; Alonso, L.; Menz, G.; Bareth, G.; Rascher, U. Angular dependency of hyperspectral measurements over wheat characterized by a novel UAV based goniometer. Remote Sens. 2015, 7, 725-746. [CrossRef]

44. Morton, D.C.; Nagol, J.; Carabajal, C.C.; Rosette, J.; Palace, M.; Cook, B.D.; Vermote, E.F.; Harding, D.J.; North, P.R. Amazon forests maintain consistent canopy structure and greenness during the dry season. Nature 2014, 506, 221-224. [CrossRef]

45. Verrelst, J.; Schaepman, M.E.; Koetz, B.; Kneubühler, M. Angular sensitivity analysis of vegetation indices derived from CHRIS/PROBA data. Remote Sens. Environ. 2008, 112, 2341-2353. [CrossRef]

46. Schalles, J.F.; Hladik, C.M.; Lynes, A.A.; Pennings, S.C. Landscape estimates of habitat types, plant biomass, and invertebrate densities in a Georgia salt marsh. Oceanography 2013, 26, 88-97. [CrossRef]

47. Baret, F.; Jacquemoud, S.; Guyot, G.; Leprieur, C. Modeled analysis of the biophysical nature of spectral shifts and comparison with information content of broad bands. Remote Sens. Environ. 1992, 41, 133-142. [CrossRef]

48. Jacquemoud, S.; Verhoef, W.; Baret, F.; Bacour, C.; Zarco-Tejada, P.J.; Asner, G.P.; François, C.; Ustin, S.L. PROSPECT+SAIL models: A review of use for vegetation characterization. Remote Sens. Environ. 2009, 113, S56-S66. [CrossRef]

49. Féret, J.B.; Gitelson, A.; Noble, S.; Jacquemoud, S. PROSPECT-D: Towards modeling leaf optical properties through a complete lifecycle. Remote Sens. Environ. 2017, 193, 204-215. [CrossRef]

50. Berger, K.; Atzberger, C.; Danner, M.; D’Urso, G.; Mauser, W.; Vuolo, F.; Hank, T. Evaluation of the PROSAIL Model Capabilities for Future Hyperspectral Model Environments: A Review Study. Remote Sens. 2018, 10, 85. [CrossRef]

51. Bsaibes, A.; Courault, D.; Baret, F.; Weiss, M.; Olioso, A.; Jacob, F.; Hagolle, O.; Marloie, O.; Bertrand, N.; Desfond, V.; et al. Albedo and LAI estimates from FORMOSAT-2 data for crop monitoring. Remote Sens. Environ. 2009, 113, 716-729. [CrossRef]

52. Koetz, B.; Baret, F.; Poilvé, H.; Hill, J. Use of coupled canopy structure dynamic and radiative transfer models to estimate biophysical canopy characteristics. Remote Sens. Environ. 2005, 95, 115-124. [CrossRef]

53. Danner, M.; Berger, K.; Wocher, M.; Mauser, W.; Hank, T. Retrieval of Biophysical Crop Variables from Multi-Angular Canopy Spectroscopy. Remote Sens. 2017, 9, 726. [CrossRef]

54. Darvishzadeh, R.; Matkan, A.A.; Ahangar, A.D. Inversion of a radiative transfer model for estimation of rice canopy chlorophyll content using a lookup-table approach. IEEE J. Sel. Top. Appl. Earth Obs. Remote Sens. 2012, 5, 1222-1230. [CrossRef]

55. Breunig, F.M.; Galvão, L.S.; Formaggio, A.R.; Epiphanio, J.C. Influence of data acquisition geometry on soybean spectral response simulated by the prosail model. Eng. Agrícola 2013, 33, 176-187. [CrossRef]

56. Baret, F.; Clevers, J.; Steven, M. The robustness of canopy gap fraction estimates from red and near-infrared reflectances: A comparison of approaches. Remote Sens. Environ. 1995, 54, 141-151. [CrossRef]

57. Richter, K.; Atzberger, C.; Vuolo, F.; Weihs, P.; d’Urso, G. Experimental assessment of the Sentinel-2 band setting for RTM-based LAI retrieval of sugar beet and maize. Can. J. Remote Sens. 2009, 35, 230-247. [CrossRef]

58. Jay, S.; Maupas, F.; Bendoula, R.; Gorretta, N. Retrieving LAI, chlorophyll and nitrogen contents in sugar beet crops from multi-angular optical remote sensing: Comparison of vegetation indices and PROSAIL inversion for field phenotyping. Field Crop Res. 2017, 210, 33-46. [CrossRef]

59. Bachmann, C.; Eon, R.; Lapszynski, C.; Badura, G.; Vodacek, A.; Hoffman, M.; Mckeown, D.; Kremens, R.; Richardson, M.; Bauch, T.; et al. A Low-Rate Video Approach to Hyperspectral Imaging of Dynamic Scenes. J. Imaging 2019, 5, 6. [CrossRef] 
60. Osgood, D.T.; Zieman, J.C. Spatial and temporal patterns of substrate physicochemical parameters in different-aged barrier island marshes. Estuar. Coast. Shelf Sci. 1993, 37, 421-436. [CrossRef]

61. Hayden, B.; Dueser, R.; Callahan, J.; Shugart, H. Long-term research at the Virginia Coast Reserve. BioScience 1991, 41, 310-318. [CrossRef]

62. Stewart, J.Q. The great Atlantic coast tides of 5-8 March 1962. Weatherwise 1962, 15, 117-120. [CrossRef]

63. Walsh, J.P. Low Marsh Succession along an Over-Wash Salt Marsh Chronosequence. Ph.D. Thesis, University of Virginia, Charlottesville, VA, USA, 1999.

64. Tyler, A.C.; Lambrinos, J.G.; Grosholz, E.D. Nitrogen inputs promote the spread of an invasive marsh grass. Ecol. Appl. 2007, 17, 1886-1898. [CrossRef]

65. Headwall E-Series Specifications. Available online: https://cdn2.hubspot.net/hubfs/145999/docs/ Hyperspec_VNIR_2017.pdf?t=1515090180800 (accessed on 8 October 2018).

66. General Dynamics Vector 20 Maritime Pan Tilt. Available online: https:/ /www.gd-ots.com/wp-content/ uploads/2017/11/Vector-20-Stabilized-Maritime-Pan-Tilt-System-1.pdf (accessed on 8 October 2018).

67. Vectornav VN-300 GPS IMU. Available online: https://www.vectornav.com/products/vn-300 (accessed on 8 October 2018).

68. BlueSky AL-3 (15m) Telescopic Mast. Available online: http://blueskymast.com/product/bsm3-w-1315al3-000/ (accessed on 9 October 2018).

69. Jacquemoud, S.; Baret, F. PROSPECT: A model of leaf optical properties spectra. Remote Sens. Environ. 1990, 34, 75-91. [CrossRef]

70. Verhoef, W. Light scattering by leaf layers with application to canopy reflectance modeling: The SAIL model. Remote Sens. Environ. 1984, 16, 125-141. [CrossRef]

71. Kuusk, A. The hot spot effect in plant canopy reflectance. In Photon-Vegetation Interactions: Applications in Optical Remote Sensing and Plant Ecology; Springer: Berlin, Germany, 1991; pp. 139-159.

72. Allen, W.A.; Gausman, H.W.; Richardson, A.J.; Thomas, J.R. Interaction of isotropic light with a compact plant leaf. JOSA 1969, 59, 1376-1379. [CrossRef]

73. Feret, J.B.; François, C.; Asner, G.P.; Gitelson, A.A.; Martin, R.E.; Bidel, L.P.; Ustin, S.L.; Le Maire, G.; Jacquemoud, S. PROSPECT-4 and 5: Advances in the leaf optical properties model separating photosynthetic pigments. Remote Sens. Environ. 2008, 112, 3030-3043. [CrossRef]

74. Darvishzadeh, R.; Skidmore, A.; Schlerf, M.; Atzberger, C. Inversion of a radiative transfer model for estimating vegetation LAI and chlorophyll in a heterogeneous grassland. Remote Sens. Environ. 2008, 112, 2592-2604. [CrossRef]

75. Atzberger, C.; Jarmer, T.; Schlerf, M.; Kötz, B.; Werner, W. Retrieval of wheat bio-physical attributes from hyperspectral data and SAILH+ PROSPECT radiative transfer model. In Proceedings of the 3rd EARSeL Workshop on Imaging Spectroscopy, Herrsching, Germany, 13-16 May 2003; pp. 473-482.

76. Verhoef, W. Theory of Radiative Transfer Models Applied in Optical Remote Sensing of Vegetation Canopies. Ph.D. Thesis, Wageningen Agricultural University, Wageningen, The Netherlands, 1989.

77. Nelder, J.A.; Mead, R. A simplex method for function minimization. Comput. J. 1965, 7, 308-313. [CrossRef]

78. He, B.; Quan, X.; Xing, M. Retrieval of leaf area index in alpine wetlands using a two-layer canopy reflectance model. Int. J. Appl. Earth Obs. Geoinf. 2013, 21, 78-91. [CrossRef]

79. Houborg, R.; Anderson, M.; Daughtry, C. Utility of an image-based canopy reflectance modeling tool for remote estimation of LAI and leaf chlorophyll content at the field scale. Remote Sens. Environ. 2009, 113, 259-274. [CrossRef]

80. Quan, X.; He, B.; Yebra, M.; Yin, C.; Liao, Z.; Zhang, X.; Li, X. A radiative transfer model-based method for the estimation of grassland aboveground biomass. Int. J. Appl. Earth Obs. Geoinf. 2017, 54, 159-168. [CrossRef]

81. Weiss, M.; Baret, F.; Myneni, R.; Pragnère, A.; Knyazikhin, Y. Investigation of a model inversion technique to estimate canopy biophysical variables from spectral and directional reflectance data. Agronomie 2000, 20, 3-22. [CrossRef]

82. Price, J.C. On the information content of soil reflectance spectra. Remote Sens. Environ. 1990, 33, $113-121$. [CrossRef]

83. Price, J.C. An approach for analysis of reflectance spectra. Remote Sens. Environ. 1998, 64, 316-330. [CrossRef] 
84. Weiss, M.; Baret, F.; Leroy, M.; Bégué, A.; Hautecoeur, O.; Santer, R. Hemispherical reflectance and albedo estimates from the accumulation of across-track sun-synchronous satellite data. J. Geophys. Res. Atmos. 1999, 104, 22221-22232. [CrossRef]

85. Bacour, C.; Jacquemoud, S.; Vogt, P.; Hosgood, B.; Andreoli, G.; Frangi, J.P. Optimal sampling configurations for the estimation of canopy properties from BRDF data acquired with the EGO/JRC. In Proceedings of the International Symposium on Physical Measurements \& Signatures in Remote Sensing, Aussois, France, 8-12 January 2001; pp. 8-12.

86. Atzberger, C.; Darvishzadeh, R.; Immitzer, M.; Schlerf, M.; Skidmore, A.; Le Maire, G. Comparative analysis of different retrieval methods for mapping grassland leaf area index using airborne imaging spectroscopy. Int. J. Appl. Earth Obs. Geoinf. 2015, 43, 19-31. [CrossRef]

87. Verrelst, J.; Rivera, J.P.; Gitelson, A.; Delegido, J.; Moreno, J.; Camps-Valls, G. Spectral band selection for vegetation properties retrieval using Gaussian processes regression. Int. J. Appl. Earth Obs. Geoinf. 2016, 52, 554-567. [CrossRef]

88. Li, L.; Cheng, Y.B.; Ustin, S.; Hu, X.T.; Riaño, D. Retrieval of vegetation equivalent water thickness from reflectance using genetic algorithm (GA)-partial least squares (PLS) regression. Adv. Space Res. 2008, 41, 1755-1763. [CrossRef]

89. Saltelli, A.; Tarantola, S.; Chan, K.S. A quantitative model-independent method for global sensitivity analysis of model output. Technometrics 1999, 41,39-56. [CrossRef]

90. Bowyer, P.; Danson, F. Sensitivity of spectral reflectance to variation in live fuel moisture content at leaf and canopy level. Remote Sens. Environ. 2004, 92, 297-308. [CrossRef]

91. Ceccato, P.; Flasse, S.; Tarantola, S.; Jacquemoud, S.; Grégoire, J.M. Detecting vegetation leaf water content using reflectance in the optical domain. Remote Sens. Environ. 2001, 77, 22-33. [CrossRef]

92. Ceccato, P.; Gobron, N.; Flasse, S.; Pinty, B.; Tarantola, S. Designing a spectral index to estimate vegetation water content from remote sensing data: Part 1: Theoretical approach. Remote Sens. Environ. 2002, 82, 188-197. [CrossRef]

93. Matheson, D.S.; Dennison, P.E. Evaluating the effects of spatial resolution on hyperspectral fire detection and temperature retrieval. Remote Sens. Environ. 2012, 124, 780-792. [CrossRef]

94. Cheng, Y.; Gamon, J.A.; Fuentes, D.A.; Mao, Z.; Sims, D.A.; Qiu, H.1.; Claudio, H.; Huete, A.; Rahman, A.F. A multi-scale analysis of dynamic optical signals in a Southern California chaparral ecosystem: A comparison of field, AVIRIS and MODIS data. Remote Sens. Environ. 2006, 103, 369-378. [CrossRef]

95. Dalponte, M.; Bruzzone, L.; Gianelle, D. Tree species classification in the Southern Alps based on the fusion of very high geometrical resolution multispectral/hyperspectral images and LiDAR data. Remote Sens. Environ. 2012, 123, 258-270. [CrossRef]

96. Hardisky, M.; Klemas, V.; Daiber, F. Remote sensing salt marsh biomass and stress detection. Adv. Space Res. 1983, 2, 219-229. [CrossRef]

97. Fernandez, S.; Vidal, D.; Simon, E.; Sole-Sugraiies, L. Radiometric characteristics of Triticum aestivum cv, Astral under water and nitrogen stress. Int. J. Remote Sens. 1994, 15, 1867-1884. [CrossRef]

(C) 2019 by the authors. Licensee MDPI, Basel, Switzerland. This article is an open access article distributed under the terms and conditions of the Creative Commons Attribution (CC BY) license (http:// creativecommons.org/licenses/by/4.0/). 